\title{
Probiotics for Mild Cognitive Impairment and Alzheimer's Disease: A Systematic Review and Meta-Analysis
}

\author{
Guangsu Zhu ${ }^{1,2} \mathbb{D}$, Jianxin Zhao ${ }^{1,2,3}$, Hao Zhang ${ }^{1,2,3,4,5}$, Wei Chen ${ }^{1,2,4}$ and Gang Wang $1,2,3, *(\mathbb{D})$ \\ 1 State Key Laboratory of Food Science and Technology, Jiangnan University, Wuxi 214122, China; \\ su1994112@163.com (G.Z.); zhaojianxin@jiangnan.edu.cn (J.Z.); zhanghao@jiangnan.edu.cn (H.Z.); \\ chenwei66@jiangnan.edu.cn (W.C.) \\ 2 School of Food Science and Technology, Jiangnan University, Wuxi 214122, China \\ 3 (Yangzhou) Institute of Food Biotechnology, Jiangnan University, Yangzhou 225004, China \\ 4 National Engineering Research Center for Functional Food, Jiangnan University, Wuxi 214122, China \\ 5 Wuxi Translational Medicine Research Center, Jiangsu Translational Medicine Research Institute Wuxi Branch, \\ Wuxi 214122, China \\ * Correspondence: wanggang@jiangnan.edu.cn; Tel.: +86-510-85912155
}

Citation: Zhu, G.; Zhao, J.; Zhang, H.; Chen, W.; Wang, G. Probiotics for Mild Cognitive Impairment and Alzheimer's Disease: A Systematic Review and Meta-Analysis. Foods 2021, 10, 1672. https://doi.org/ 10.3390 /foods 10071672

Academic Editor:

Joaquín Bautista-Gallego

Received: 9 June 2021

Accepted: 19 July 2021

Published: 20 July 2021

Publisher's Note: MDPI stays neutral with regard to jurisdictional claims in published maps and institutional affiliations.

Copyright: (c) 2021 by the authors. Licensee MDPI, Basel, Switzerland. This article is an open access article distributed under the terms and conditions of the Creative Commons Attribution (CC BY) license (https:/ / creativecommons.org/licenses/by/ $4.0 /)$.

\begin{abstract}
Accumulating evidence from animal studies supports the potential role of probiotics and prebiotics in alleviating neurodegenerative diseases. However, whether dietary supplementation with probiotics improves cognitive function in patients with Alzheimer's disease (AD) or mild cognitive impairment (MCI) is unclear. We searched literature databases for relevant randomized control trials and compared the outcomes between control/placebo and intervention groups. The results of the included studies were meta-analyzed using a random-effects model, with standardized mean differences (SMDs) and 95\% confidence intervals (CIs) calculated as summary statistics. We also performed a risk-of-bias assessment, sensitivity analysis and subgroup analysis. Among the 294 articles identified, eight articles involving 174 patients with AD and 446 with MCI were included in the qualitative synthesis and seven studies were meta-analyzed. Our analysis detected high between-group heterogeneity (SMD $=0.43,95 \% \mathrm{CI}-0.02-0.88, p<0.0001, I^{2}=86.4 \%$ ) in cognitive function across the included studies. Subgroup analyses identified a significant effect of probiotics on cognitive function only in the studies involving people with $\mathrm{MCI}\left(I^{2}=44 \%, p=0.15\right.$ for heterogeneity, $p=0.0002$ for overall effect). Our findings suggest that dietary supplementation with probiotics improves cognitive function, especially in people with MCI.
\end{abstract}

Keywords: probiotics; Alzheimer's disease; mild cognitive impairment; cognition; meta-analysis

\section{Introduction}

Alzheimer's disease (AD) is the most common neurodegenerative disease, hallmarks of which include amyloid plaques and neurofibrillary tangles [1]. Despite the existence of treatments that can alleviate these symptoms, no therapeutic approach has been proven to completely halt AD progression [2]. According to the 2020 World Alzheimer Report, the current annual healthcare cost for AD treatment is $\$ 1$ trillion, which is predicted to double by 2030 .

Due to the gradual nature of AD progression, it is imperative to explore and develop intervention strategies for early-stage AD [1]. In the past decade, an increasing number of randomized control trials (RCTs) have demonstrated promising findings regarding dietary interventions for AD, especially probiotic and prebiotic supplementation, which has been shown to delay AD progression [3,4]. Regulation of the gut-brain axis has been proposed as an evolving therapeutic approach for neurodegenerative disorders such as AD [5]. With the accumulation of knowledge regarding the changes in gut microbiota in patients with AD in recent years, research has increasingly focused on more specific 'gut-microbiota-targeted' intervention strategies for AD progression. 
According to the consensus statement of the International Scientific Association for Probiotics and Prebiotics (ISAPP), probiotics are defined as 'live microorganisms that, when administered in adequate amounts, confer a health benefit on the host' [6]; the definition of a prebiotic is "a substrate that is selectively utilized by host microorganisms conferring a health benefit" [7]; and the definition of a synbiotic is "a mixture comprising live microorganisms and substrate(s) selectively utilized by host microorganisms that confers a health benefit on the host" [8]. Given their ability to modulate the structure and composition of the gut microbiota and impart health benefits, probiotics and prebiotics supplementation provide a novel approach for the prevention or treatment of certain diseases. In fact, several studies have provided compelling evidence supporting the neuroprotective effects of probiotics and prebiotics in neurological disorders [9-11].

Consistent with the burgeoning interest, several reviews of the efficacy of probiotic supplementation for neurological disorders/AD have been published, including one systematic review [12] and three meta-analyses [13-15]. Despite providing comprehensive evaluations of the early literature in this field and their importance for guiding clinical trials, these reviews have several limitations. For example, the meta-analyses yielded contradictory findings, with one reporting no ameliorative effect of probiotics on cognitive function [13] and the other two reporting improvement in cognitive function after the administration of probiotics [14,15]. These meta-analyses only included studies published before 2018 that investigated the beneficial effects of probiotics and prebiotics. We update the data by adding evidence from recently published studies [16-18], including one study that evaluated the protective effects of a synbiotic [16]. Furthermore, two of the three metaanalyses $[14,15]$ included a study that combined mild cognitive impairment (MCI) and AD as a single outcome in their quantitative analyses, which might have yielded inaccurate findings. Notably, Jenifer et al. [13] only included three studies in their meta-analysis and did not assess publication bias, which might account for the high between-study heterogeneity reported. In addition, Cristofer et al. [15] did not include a subgroup analysis in their meta-analysis, despite observing high between-group heterogeneity. They also missed the most authoritative biomedical database, Embase, when searching for eligible literature.

To address these limitations, we conducted a systematic review and meta-analysis with more recently published clinical trials to evaluate the effects of probiotic and prebiotic supplementation on people with MCI and AD. To elucidate the possible beneficial effects of probiotics and prebiotics on cognitive function and neuroinflammation, we included a comparison of the treatment outcomes with outcomes in the control/placebo groups.

\section{Materials and Methods}

\subsection{Search Strategy and Selection Criteria}

This systematic review and meta-analysis is reported according to the Preferred Reporting Items for Systematic Reviews and Meta-Analyses (PRISMA) statement [19]. The PRISMA checklist is shown in Table S1. It has also been registered in the International Prospective Register of Systematic Reviews (Number CRD42020188410). We searched PubMed, Embase, Cochrane, Web of Science and ClinicalTrials.gov for relevant studies published in English between 1 July 1984 and 8 April 2021. The following MeSH terms and combined text were used to search the databases: Alzheimer's disease, cognitive dysfunction, mild cognitive impairment, probiotics, prebiotics, synbiotics and randomized controlled trial. The search strategies used in specific databases are provided in Supplementary S1 We also manually searched the reference lists of the retrieved studies for relevant articles.

\subsection{Eligibility Criteria}

RCTs were eligible if they meet the PICO criteria (listed in Table 1). Studies were included if they (1) were randomized clinical trials $(\mathrm{S})$ conducted in participants $(\mathrm{P})$ with AD or MCI; (2) included an intervention (I) with probiotics, prebiotics or synbiotics; (3) compared the efficacy of the intervention with a control (C) or placebo; and (4) reported the 
main outcomes $(\mathrm{O})$ of cognitive function (assessed using a rating scale) and gut microbiota diversity and composition. The additional outcomes reported could be changes in metabolic variables and inflammatory and oxidative stress biomarkers.

Table 1. The PICOS criteria for inclusion and exclusion of studies.

\begin{tabular}{|c|c|c|}
\hline Parameter & Inclusion Criteria & Exclusion Criteria \\
\hline Participants & $\begin{array}{c}\text { Individuals diagnosed with } \\
\text { Alzheimer disease or mild cognitive } \\
\text { impairment, based on any recognized } \\
\text { diagnostic criteria. }\end{array}$ & $\begin{array}{l}\text { People without cognitive impairment } \\
\text { or combined with other types of } \\
\text { dementia, e.g., vascular dementia, } \\
\text { frontotemporal dementia. }\end{array}$ \\
\hline Intervention & $\begin{array}{l}\text { Probiotic or synbiotics, orally or } \\
\text { enterally administered, with no } \\
\text { restriction on strains, doses, } \\
\text { frequency and duration } \\
\text { of intervention. }\end{array}$ & $\begin{array}{l}\text { Studies that compared or combined } \\
\text { probiotics administration with drugs } \\
\text { or other therapeutic interventions. }\end{array}$ \\
\hline Comparison & $\begin{array}{l}\text { Usual care, placebo, or other } \\
\text { interventions without any } \\
\text { probiotics/prebiotic/symbiotic } \\
\text { supplementation. }\end{array}$ & $\mathrm{N} / \mathrm{A}$ \\
\hline Outcomes & $\begin{array}{l}\text { Primary outcome: cognitive function, } \\
\text { measured using an appropriate, } \\
\text { validated cognitive test; gut } \\
\text { microbiota diversity and composition. } \\
\text { Secondary outcome: changes in } \\
\text { metabolic variables and inflammatory } \\
\text { and oxidative stress biomarkers. }\end{array}$ & $\begin{array}{l}\text { Reported data could not be } \\
\text { calculated based on the information } \\
\text { in the article. }\end{array}$ \\
\hline Study design & Randomized controlled trials (RCTs) & $\begin{array}{c}\text { Case reports, review articles, } \\
\text { systematic literature reviews, } \\
\text { editorial pieces, comments, news } \\
\text { and letters. }\end{array}$ \\
\hline
\end{tabular}

Note: N/A, not applicable.

Studies were excluded if they (1) did not contain an AD or MCI cohort; (2) did not list the diagnostic criteria applied for $\mathrm{AD}$ or MCI; (3) were observational or retrospective; (4) did not evaluate an intervention strategy; and (5) contained duplicate study data.

The titles and/or abstracts of the retrieved studies were imported to EndNote X9 to assess for duplication. After eliminating the duplicate studies, all remaining studies were screened against the inclusion and exclusion criteria. The full texts of the studies that satisfied the inclusion criteria were retrieved. For the excluded studies, the reasons for exclusion were recorded. Two investigators (Guangsu Zhu and Gang Wang) independently reviewed the study titles and abstracts, and a third investigator (Jianxin Zhao) resolved disagreements.

\subsection{Data Extraction}

Data extraction was performed and crosschecked independently by two investigators (Guangsu Zhu and Gang Wang). Any disagreements were discussed with the third investigator (Jianxin Zhao). No grey literature sources were assessed in this review. The following data were extracted from the included studies: (1) general information (i.e., title, authors, publication year, trial registration number and country); (2) participant information (i.e., sample size, age, group, sex, participant demographics and baseline characteristics); (3) methodological information (i.e., study design, intervention and comparisons, treatment allocation, intervention description and trial period duration); and (4) result-related information (i.e., recruitment; main outcome data, such as cognitive function and gut microbiota composition and diversity; additional outcome data, such as metabolic variables, inflammatory biomarkers and oxidative stress; recorded adverse events; and study completion rates). 


\subsection{Risk-of-Bias Assessment}

The risk of bias for each RCT was evaluated using the specific questions listed in the Cochrane risk-of-bias tool [20]. No study was excluded based on risk-of-bias assessment. Two investigators (Guangsu Zhu and Gang Wang) independently performed the assessment, and a third investigator (Jianxin Zhao) resolved disagreements.

\subsection{Statistical Analysis}

Meta-analysis was performed using the 'metan' command in Stata software version 14.0 (StataCorp, TX, USA), when two or more studies reported the same outcome. As cognitive function was measured using different rating scales in the included studies, its data were converted to standardized mean differences (SMDs) between the intervention and placebo groups. The effects of intervention in each included study were assessed by the changes from baseline. The SMDs and 95\% confidence intervals (CIs) were calculated using a random-effects model.

Statistical heterogeneity across studies was assessed using the $I^{2}$ statistic, with $I^{2}$ values $>50 \%$ indicating moderate-to-high heterogeneity [21]. To explore the potential source of heterogeneity, subgroup analyses based on the disease severity, type of cognitive rating scale and number of intervention strains (single vs. multiple) were performed using Review Manager version 5.3 (Cochrane Collaboration, Oxford, UK).

To test the robustness of the results, a sensitivity analysis was performed using the leave-one-out method [22]. Publication bias was assessed by constructing a funnel plot with Begg's and Egger's tests.

\section{Results}

\subsection{Literature Search and Study Selection}

Two hundred and ninety-four articles were identified from the initial database screen and 157 remained after the removal of duplicate results (Figure 1). Then, three additional articles were added by manually searching the key articles included in reference list. Furthermore, 132 articles were excluded based on title and abstract screening and 28 fulltext articles were assessed for eligibility. Subsequently, 20 articles were excluded for reasons detailed in the PRISMA flowchart (Figure 1). Ultimately, eight articles [16-18,23-27] were included in the qualitative synthesis (systematic review). One article [16] did not provide sufficient data for meta-analysis; therefore, only the remaining seven articles were included in the meta-analysis. Notably, one article [27] reported results from three independent studies using different cohort, which were regarded as three separate studies in the following quantitative analysis.

\subsection{Characteristics of the Included Studies}

The study characteristics of interest, including the country and type of study, population and diagnostic criteria, number and age of participants, proportion of female participants, intervention, species and dosage of probiotics/prebiotics, duration of the intervention, assessed outcomes and main findings, are presented in Tables 2 and 3. 


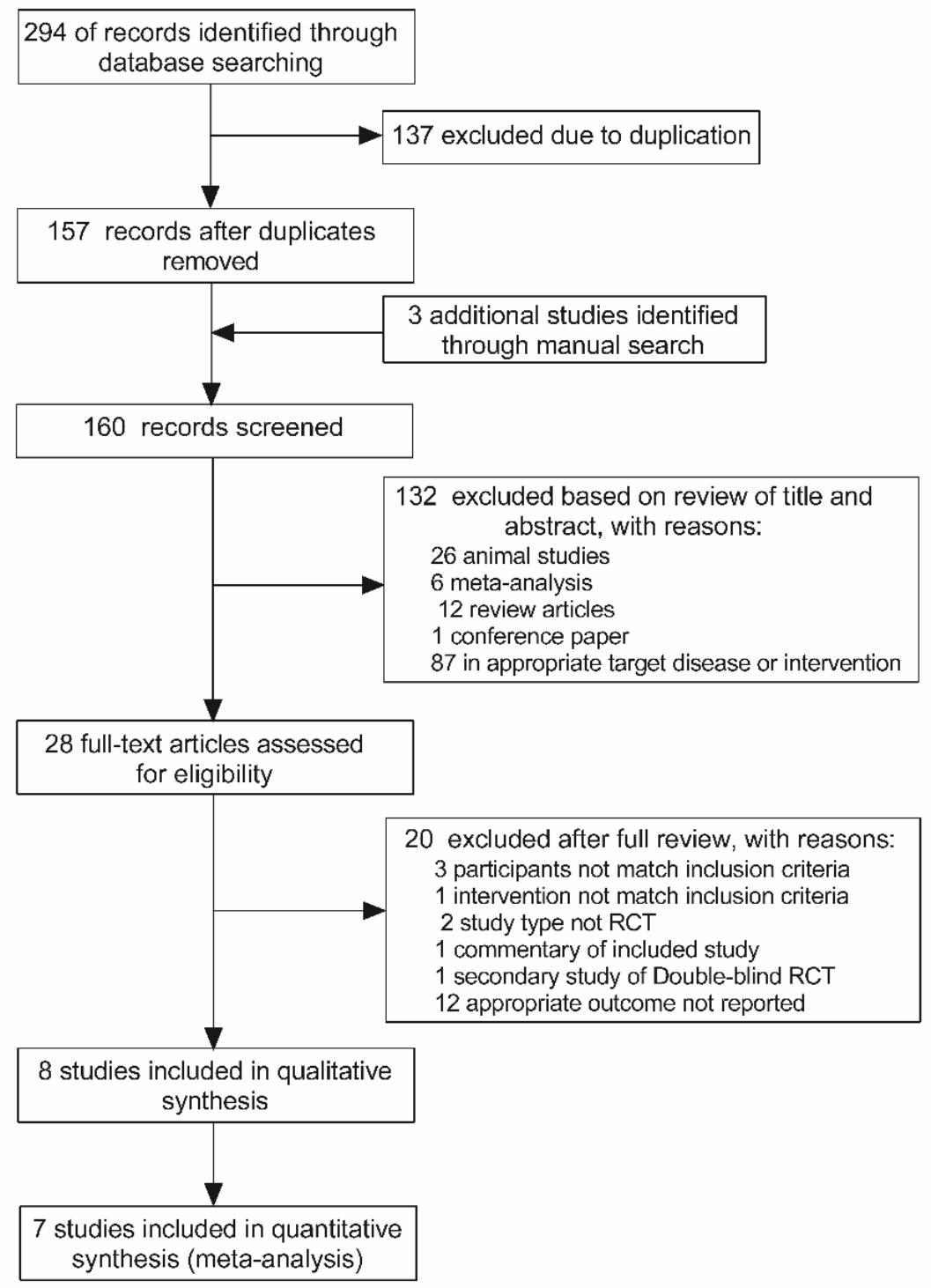

Figure 1. Flowchart illustrating the study selection process. 
Table 2. Characteristics of the included studies.

\begin{tabular}{|c|c|c|c|c|c|c|c|c|c|c|c|c|c|c|c|}
\hline \multirow[b]{3}{*}{ Study } & \multirow[b]{3}{*}{ Country } & \multirow[b]{3}{*}{ Study Type } & \multirow[b]{3}{*}{ Population } & \multirow[b]{3}{*}{ Diagnose Criteria } & \multicolumn{6}{|c|}{ Participants } & \multirow{2}{*}{\multicolumn{5}{|c|}{ Assessed Outcomes }} \\
\hline & & & & & \multicolumn{2}{|c|}{$\begin{array}{c}\text { Subjects } \\
(n)\end{array}$} & \multicolumn{2}{|c|}{$\begin{array}{c}\text { Age } \\
\text { (M \& SD) }\end{array}$} & \multicolumn{2}{|c|}{$\begin{array}{l}\text { Gender } \\
(\mathrm{M} / \mathrm{F})\end{array}$} & & & & & \\
\hline & & & & & $\begin{array}{l}P \\
P\end{array}$ & $\mathrm{C}$ & $P$ & C & $P$ & c & Intervention & Duration & Primary & Secondary & Main Findings \\
\hline $\begin{array}{l}\text { Agahi et al. } \\
\text { (2018) }\end{array}$ & Iran & $\begin{array}{l}\text { Double-blind } \\
\text { RCT }\end{array}$ & $\begin{array}{l}\text { 48 AD individuals, } \\
\text { aged } 65-90 \text { years }\end{array}$ & $\begin{array}{c}\text { NINDS-ADRDA } \\
\text { criteria }\end{array}$ & 25 & 23 & $\begin{array}{l}79.70 \\
(1.72)\end{array}$ & $\begin{array}{l}80.57 \\
(1.79)\end{array}$ & $7 / 18$ & $10 / 13$ & $\begin{array}{l}\text { Probiotic, } \\
2 \text { capsules daily }\end{array}$ & 12 weeks & TYM & $\begin{array}{l}\text { TAC, GSH, MDA, IL-6, IL-10, } \\
\text { TNF- } \alpha, 8-\mathrm{OHdG}, \mathrm{NO}, \mathrm{BMI}\end{array}$ & $\begin{array}{l}83.5 \% \text { of the patients showed severe } \\
\text { AD; no significant changes were } \\
\text { detected both in cognitive and } \\
\text { biochemical indications anter } \\
\text { probiotic supplementation. }\end{array}$ \\
\hline $\begin{array}{l}\text { Akbari et al. } \\
(2016)\end{array}$ & Iran & $\begin{array}{l}\text { Double-blind } \\
\text { RCT }\end{array}$ & $\begin{array}{l}60 \mathrm{AD} \text { individuals, } \\
\text { aged } 60-90 \text { years }\end{array}$ & $\begin{array}{l}\text { NINDS-ADRDA } \\
\text { criteria }\end{array}$ & 30 & 30 & $\begin{array}{l}77.67 \\
(2.62)\end{array}$ & $\begin{array}{l}82.00 \\
(1.69)\end{array}$ & $6 / 24$ & $6 / 24$ & $\begin{array}{l}\text { Probiotic, } 200 \mathrm{~mL} \\
\text { milk daily }\end{array}$ & 12 weeks & MMSE & $\begin{array}{l}\text { TAC, GGH, MDA, h-SCRP, NO, } \\
\text { FPG, TG, TC, LDL, HDL, Insulin, } \\
\text { HOMA-IR, HOMA-B, } \\
\text { QUICKI, BMI- }\end{array}$ & $\begin{array}{l}\text { Cognitite function and some } \\
\text { metabolic tatuses were positively } \\
\text { affected by proboiotic } \\
\text { supplementation in } A D \text { patients. }\end{array}$ \\
\hline $\begin{array}{l}\text { Hwang et al. } \\
(2019)\end{array}$ & Korea & $\begin{array}{l}\text { Double-blind } \\
\text { RCT }\end{array}$ & $\begin{array}{l}100 \mathrm{MCI} \\
\text { individuals, aged } \\
55-85 \text { years }\end{array}$ & $\begin{array}{l}\text { Diagnostic and } \\
\text { Statatisical Manual } \\
\text { of Mental } \\
\text { Disorders, 5th } \\
\text { edition (DSM-5) }\end{array}$ & 50 & 50 & $\begin{array}{l}68.0 \\
(5.12)\end{array}$ & $\begin{array}{l}69.2 \\
(7.00)\end{array}$ & $20 / 30$ & $14 / 36$ & $\begin{array}{l}\text { Probiotic, } \\
2 \text { capsules daily }\end{array}$ & 12 weeks & $\begin{array}{l}\text { CNT (VLT, } \\
\text { ACPT, DST) }\end{array}$ & $\begin{array}{l}\text { BDNF, gut microbiota, TC, blood } \\
\text { glucose, BMI, blood pressure, pulse } \\
\text { rate, ALI, AST, ALP, Albumin, } \\
\text { BUN, Uric acid, Creatinine, }\end{array}$ & $\begin{array}{l}\text { DW2009 supplementation can } \\
\text { enhance cognitive function in } \\
\text { MCI individuals. }\end{array}$ \\
\hline $\begin{array}{l}\text { Kobayashi et al. } \\
\text { (2019) }\end{array}$ & Japan & $\begin{array}{l}\text { Double-blind } \\
\text { RCT }\end{array}$ & $\begin{array}{l}121 \mathrm{MCI} \\
\text { individuals, aged } \\
50-80 \text { years }\end{array}$ & MMSE score, 22-27 & 61 & 60 & $\begin{array}{l}61.5 \\
(6.83)\end{array}$ & $\begin{array}{l}61.6 \\
(6.37)\end{array}$ & $30 / 31$ & $30 / 30$ & $\begin{array}{c}\text { Probiotic, } \\
2 \text { capsules daily }\end{array}$ & 12 weeks & MMSE & 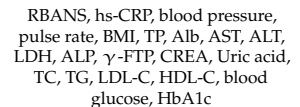 & $\begin{array}{l}\text { No significiant difference } \\
\text { was observed. }\end{array}$ \\
\hline $\begin{array}{l}\text { Reza et al. } \\
(2018)\end{array}$ & Iran & $\begin{array}{l}\text { Double-blind } \\
\text { RCT }\end{array}$ & $\begin{array}{l}53 \mathrm{AD} \text { individuals, } \\
\text { aged 65-90 years } \\
\text { (mean } \\
\text { age76.2-78.5) }\end{array}$ & $\begin{array}{l}\text { NINDS-ADRDA } \\
\text { criteria }\end{array}$ & 27 & 26 & $\begin{array}{l}76.2 \\
(8.1)\end{array}$ & $\begin{array}{l}78.5 \\
(8.0)\end{array}$ & Un & Un & $\begin{array}{l}\text { Probiotic, } 200 \mu \mathrm{\mu g} \\
\text { selenium + probiotic } \\
\text { capsule daily }\end{array}$ & 12 weeks & MMSE & $\begin{array}{l}\text { TAC, GSH, hs-CRP, Insulin, } \\
\text { HOMA-IR, QUCKCK, T, NO, FPG, } \\
\text { MDA, LDL, VLLL, HDL, TC, } \\
\text { HDL, BMI }\end{array}$ & $\begin{array}{l}\text { Cognitive function and some } \\
\text { metabolic profiles were improved } \\
\text { by probiotic and selenium } \\
\text { co-supplementation in AD patients. }\end{array}$ \\
\hline $\begin{array}{l}\text { Sanborn et al. } \\
(2020)\end{array}$ & USA & $\begin{array}{l}\text { Double-blind } \\
\text { RCT }\end{array}$ & $\begin{array}{l}42 \mathrm{MCl} \text { individuals } \\
\text { and 103 healthy } \\
\text { individuals, aged } \\
52-75 \text { years }\end{array}$ & NIHTB & 76 & 69 & $\begin{array}{l}64.6 \\
(5.58)\end{array}$ & $\begin{array}{l}64.1 \\
(5.32)\end{array}$ & $18 / 24$ & $41 / 62$ & $\begin{array}{l}\text { Probiotic, } \\
2 \text { capsules daily }\end{array}$ & 90 days & $\begin{array}{l}\text { NIH Toolbox [M1] } \\
\text { scores (picture, flanker, } \\
\text { case sort, list } \\
\text { sort, pattern) } \\
\text { RBANS Immediate }\end{array}$ & BMI, blood pressure & $\begin{array}{l}\text { Probiotic supplementation } \\
\text { improved the cognition score in } \\
\text { subjects with cognitive impairment. }\end{array}$ \\
\hline $\begin{array}{l}\text { Xiao et al. } \\
(2020)\end{array}$ & Japan & $\begin{array}{l}\text { Double-blind } \\
\text { RCT }\end{array}$ & $\begin{array}{l}\text { 80 MCI individuals, } \\
\text { aged 50-79 years }\end{array}$ & $\begin{array}{l}\text { lower RBANS score } \\
\text { \& MMSE score > } 22\end{array}$ & 40 & 40 & $\begin{array}{l}61.3 \\
(7.7)\end{array}$ & $\begin{array}{l}60.9 \\
(6.9)\end{array}$ & $19 / 21$ & $20 / 20$ & $\begin{array}{l}\text { Probiotic, } \\
2 \text { capsules daily }\end{array}$ & 16 weeks & $\begin{array}{l}\text { RBANS (Immediate } \\
\text { memory, Visuospa- } \\
\text { tial/Constructional, } \\
\text { Language, Attention, } \\
\text { Delayed memory) }\end{array}$ & $\begin{array}{l}\text { JMCIS score, blood pressure, pulse } \\
\text { rate, BMI, }\end{array}$ & $\begin{array}{l}\text { B. breve A1 supplementation } \\
\text { significantly improved memory } \\
\text { functions of suspected } \\
\text { MCI subjects. }\end{array}$ \\
\hline Ton et al. (2020) & Brazil & $\begin{array}{l}\text { Double-blind } \\
\text { RCT }\end{array}$ & $\begin{array}{l}13 \text { AD individuals, } \\
\text { aged } 71-85 \text { years }\end{array}$ & $\begin{array}{l}\text { NINDS-ADRDA } \\
\text { criteria }\end{array}$ & 13 & 0 & $78.7(3)$ & $\mathrm{N} / \mathrm{A}$ & $2 / 11$ & N/A & $\begin{array}{l}\text { Synbiotic, } \\
2 \mathrm{~mL} / \mathrm{kg} \cdot \mathrm{bw} \\
\text { milk daily }\end{array}$ & 90 days & MMSE & $\begin{array}{l}\text { IL-6, IL-8, IL-1b, IL-12p70, TNF- } \alpha, \\
\text { IL-10, RoS, AOPP, MMP, p53, BMI, } \\
\text { Cleaved PARP expression }\end{array}$ & $\begin{array}{l}\text { Synbiotic supplementation } \\
\text { improved cognitive deficits, } \\
\text { systemic inflammation, oxidative } \\
\text { stress, and blood cell damage in } \\
\text { AD patients. }\end{array}$ \\
\hline
\end{tabular}

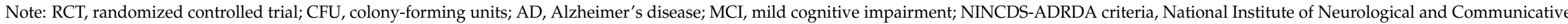

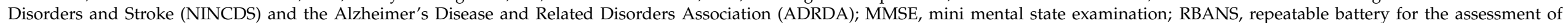

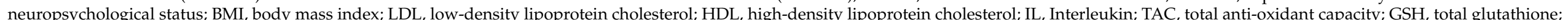

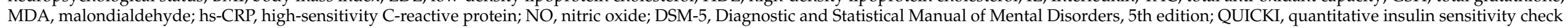

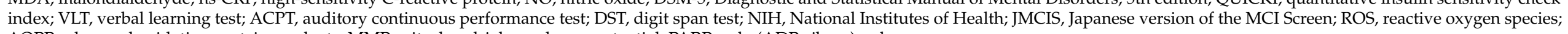
AOPP, advanced oxidation protein products; MMP, mitochondrial membrane potential; PARP, poly (ADP-ribose) polymerase 
Table 3. Species and dosage of probiotic/prebiotic used in the included studies.

\begin{tabular}{ccc}
\hline Study & Species of Probiotic/Prebiotic & Dosage \\
\hline & L. fermentum, L. plantarum, B. lactis, \\
Agahi et al. (2018) & L. acidophilus, B. bifidum, B. longum, B. bifidum, & $3 \times 10^{9} \mathrm{CFU} /$ day \\
B. longum & \\
Akbari et al. (2016) & L. acidophilus, L. casei, B. bifidum, L. fermentum & $2 \times 10^{9} \mathrm{CFU} / \mathrm{g}$ \\
Hwang et al. (2019) & L. plantarum C29 (DW2009) & $1 \times 10^{10} \mathrm{CFU} /$ day \\
Kobayashi et al. (2019) & B. breve A1 & $2.0 \times 10^{10} \mathrm{CFU} /$ day \\
Reza et al. (2018) & L. acidophilus, B. bifidum, B. longum & $2 \times 10^{9} \mathrm{CFU} /$ day \\
Sanborn et al. (2020) & L. rhamnosus GG & $2 \times 10^{10} \mathrm{CFU} /$ day \\
Xiao et al. (2020) & B. breve A1 & $2 \times 10^{10} \mathrm{CFU} /$ day \\
& $4 \%$ kefir grains containing Acetobacter aceti, \\
Acetobacter spp., L. delbrueckii, L. fermentum, \\
L. fructivorans, Enterococcus faecium, \\
\\
Leuconostoc spp., L. kefiranofaciens, Candida \\
famata \& Candida krusei
\end{tabular}

Note: L. = Lactobacillus; B. = Bifidobacterium.

As shown in Table 2, all eight of the included studies were published in the past 5 years. Among these, four studies [16,23-25] included patients with AD (174 subjects) and the other four $[17,18,26,27]$ included people with MCI (446 subjects) aged 50-90 years. In seven of the eight studies, the proportion of female to male participants was higher, whereas one study did not report this data [25]. Three studies were conducted in Iran [23-25], one in Korea [26,27] and one in Japan [26,27] in 2019. In 2020, Sanborn et al. [17] investigated the effect of the well-known commercial strain Lactobacillus rhamnosus GG on cognitive function in the USA, and Ton et al. [16] evaluated the beneficial effects of traditional Kefir grain (synbiotic) supplementation in patients with AD in Brazil.

The intervention duration in most of the included studies [23-27] was 12 weeks, except for three studies. Two [16,17] of these three studies had an intervention duration of 90 days and one [18] had a longer duration of 16 weeks. Only one study [16] tested synbiotics as the dietary intervention. Four of the seven studies $[17,18,26,27]$ tested a single strain, whereas the others [23-25] tested multiple strains of probiotics. Importantly, as presented in Table 3, all of the strains were of Lactobacillus and Bifidobacterium, the two most wellknown and widely used probiotic genera. Six of the included studies $[17,18,23,25-27]$ used encapsulated probiotics, whereas the other two $[16,24]$ used pasteurized milk enriched with probiotics. In terms of dosage, all of the intervention group participants received a daily probiotic dose of $2 \times 10^{9} \mathrm{CFU}$ or more to ensure the activity of probiotics. Notably, most of the studies (except one [16]) applied a matched control/placebo intervention which was identical in appearance, taste and smell.

The primary outcome of all of the included studies was cognitive function, mainly evaluated using mini mental state examination (MMSE) scoring. The secondary outcomes assessed in most of the studies were nutritional status, oxidative stress, metabolic profiles and inflammation biomarkers. Notably, only Hwang et al. [26] reported the changes in gut microbiota.

With regard to the primary outcome, five studies [16,18,24-26] observed significant improvement in cognitive function after treatment with probiotics/synbiotics, whereas one study [23] found no significant change. Notably, mixed findings were reported in two studies, Kobayashi et al. [27] and Sanborn et al. [17]. Similarly, the secondary outcome results were also inconsistent across the studies. Notably, DW2009 administration significantly increased the concentration of serum brain-derived neurotrophic factor $(p=0.007)$ and enriched the relative abundance of Lactobacillus spp. $(p=0.045)$. However, no statistically significant change was observed in the relative abundances of Bifidobacterium spp. ( $p=0.789)$ and Clostridium spp. $(p=0.936)$ after the interventions [26]. 


\subsection{Risk-of-Bias Assessment}

The risk-of-bias assessment results for each included study are shown in Figure 2. Given that all eight of the included studies were double-blinded (participants and researchers) RCTs, they were all classified as having a low risk of selection and performance bias. However, $37.5 \%$ of the studies $[23,25,26]$ did not describe the concealment of allocation and/or the blinding of outcome assessment. Two studies $[16,17]$ did not mention whether the evaluators were blinded to the intervention allocation and were thus classified as having a high risk of detection bias. None of the included studies stopped their trials early and thus were all assigned a low risk of reporting bias. Notably, one study [16] only enrolled 13 participants and did not include a matched placebo group. As such, it was classified as having a high risk of attrition bias and other bias. Overall, based on the results for all six domains of the risk-of-bias tool, three studies $[18,24,27]$ showed a low overall risk of bias, suggesting that these trials implemented strict procedures.
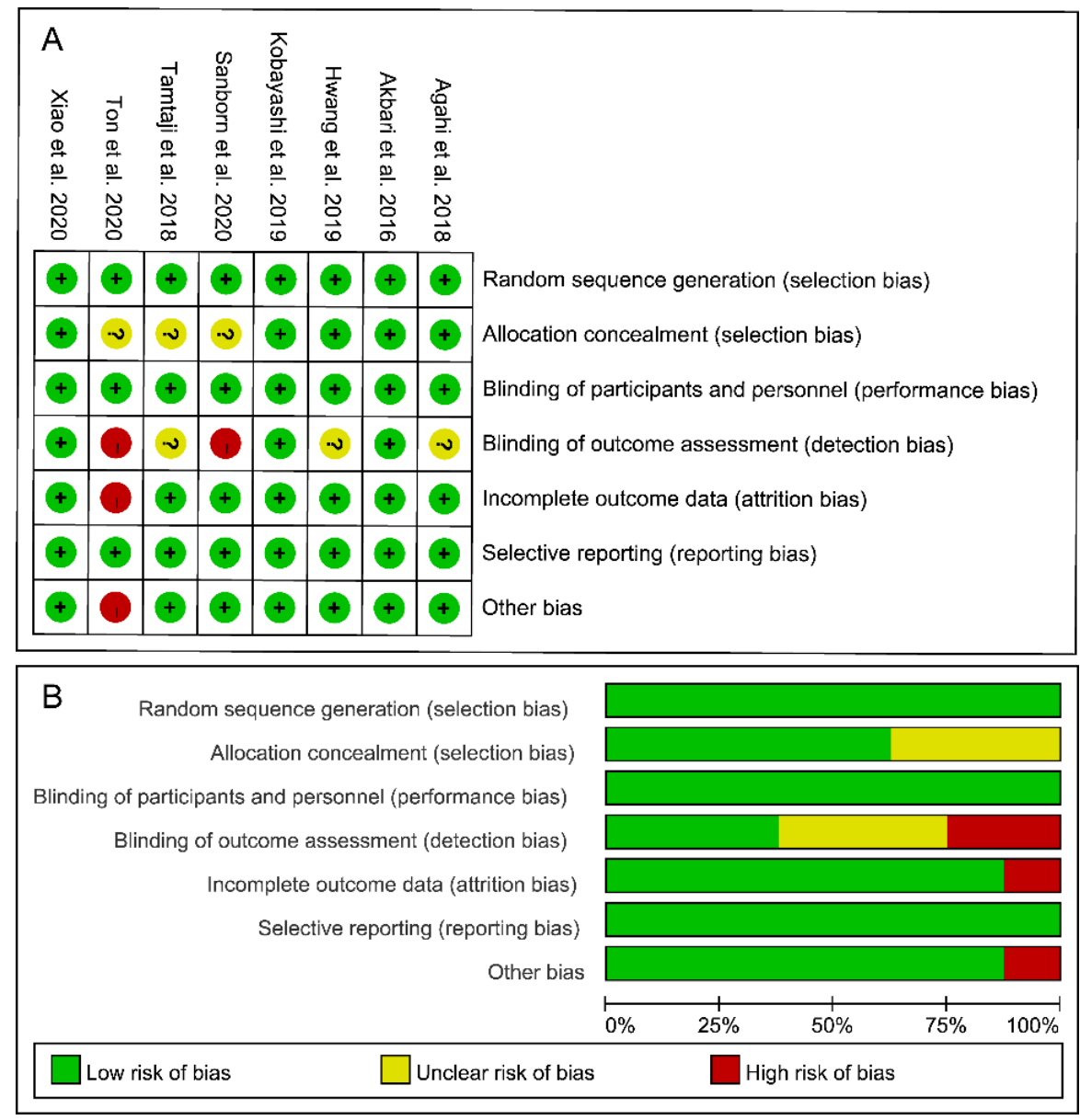

Figure 2. Risk of bias assessment for the included studies. (A) Risk of bias summary. (B) Risk of bias graph. Note: "+": low risk, "?": unclear risk, "-": high risk.

\subsection{Main Findings of Meta-Analysis}

In total, seven trials (included nine studies) provided sufficient data for a meta-analysis. In a pooled analysis of all included nine studies, a random-effects model was used when comparing the effects of probiotic and placebo treatments on cognition assessed using different rating scales. The results revealed high between-group heterogeneity $(\mathrm{SMD}=0.43$, $95 \% \mathrm{CI}=-0.02-0.88, p<0.0001, I^{2}=86.4 \%$ ) in the forest plot (Figure 3), indicating the inconsistency of results across the included studies. 


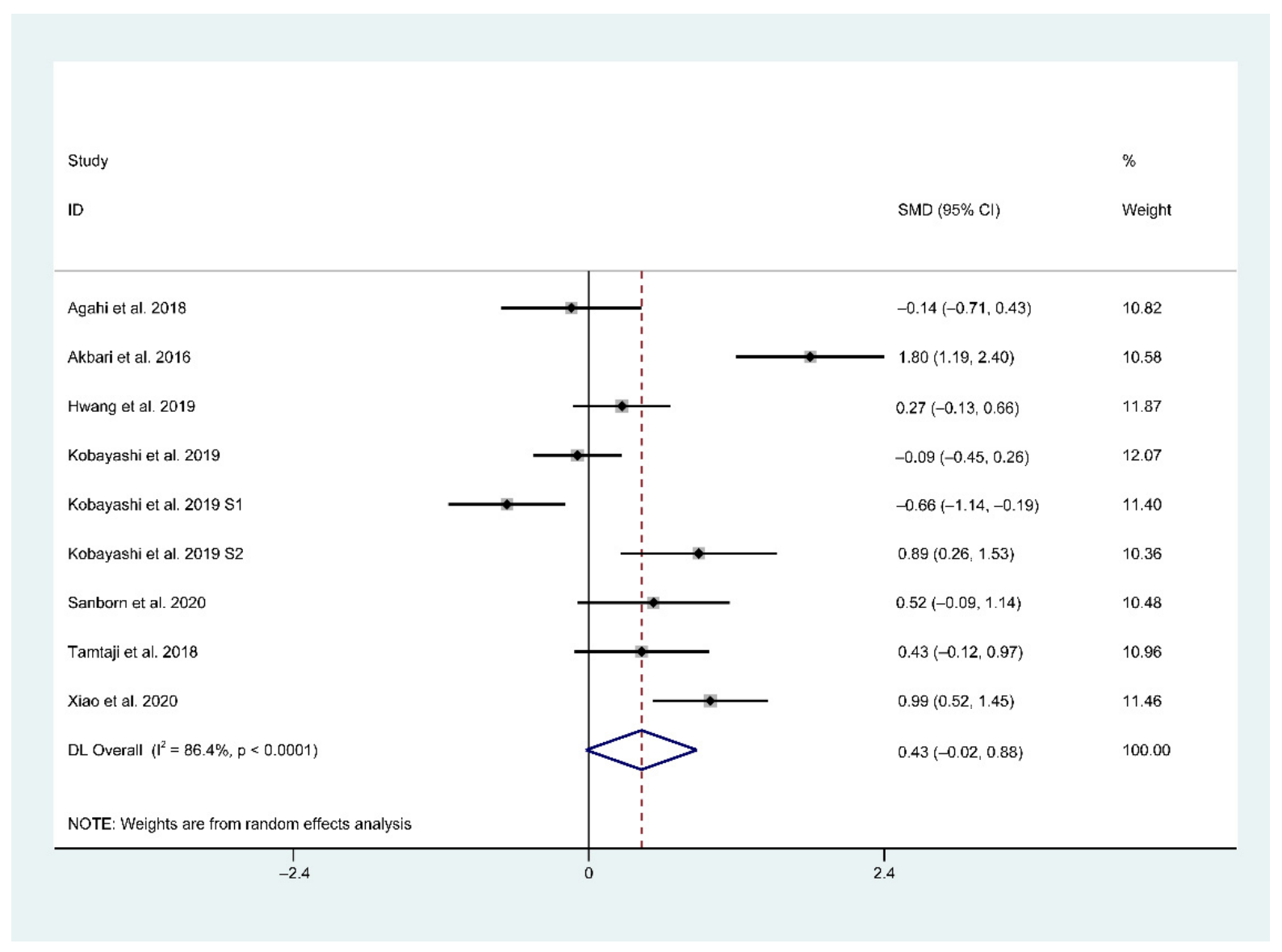

Figure 3. Forest plot of standardized mean difference (SMD) of probiotics on cognition. Weights were assigned according to the number of subjects and SD using STATA 14. A random-effect model was applied to the meta-analysis. The sizes of the data markers represent the weight of each study, and the diamond indicates the overall estimated effect. SMD, standardized mean difference.

\subsection{Subgroup Analyses}

To investigate the potential sources of between-study heterogeneity, three independent subgroup analyses were performed. As shown in Figure 4, the between-study heterogeneity $\left(p=0.57, I^{2}=0 \%\right)$ decreased when the subgroups were stratified by disease type (AD vs. MCI). Similarly, heterogeneity $\left(p=0.55, I^{2}=0 \%\right)$ in the random-effects model decreased when the subgroups were stratified by cognitive rating scales (MMSE vs. non-MMSE). Consistently, the analysis results of the subgroups stratified by 'single vs. multiple' strain intervention showed reduced heterogeneity $\left(p=0.65, I^{2}=0 \%\right)$. However, none of these subgroup analysis results were statistically significant. A statistically significant effect on cognition was only observed in the subset of studies which included people with MCI $\left(I^{2}=44 \%, p=0.15\right.$ for heterogeneity, $p=0.0002$ for overall effect $)$.

\subsection{Publication Bias Assessment and Sensitivity Analysis}

Although the funnel plot was slightly asymmetrical, no publication bias for cognitive function was detected based on the results of the Egger's and Begg's tests (Egger's test: $p=0.205$, Begg's test: $p=0.144$; Figure 5). A further sensitivity analysis revealed that the overall effects of probiotics on cognition was affected by one or more studies exclusions (Figure 6). 

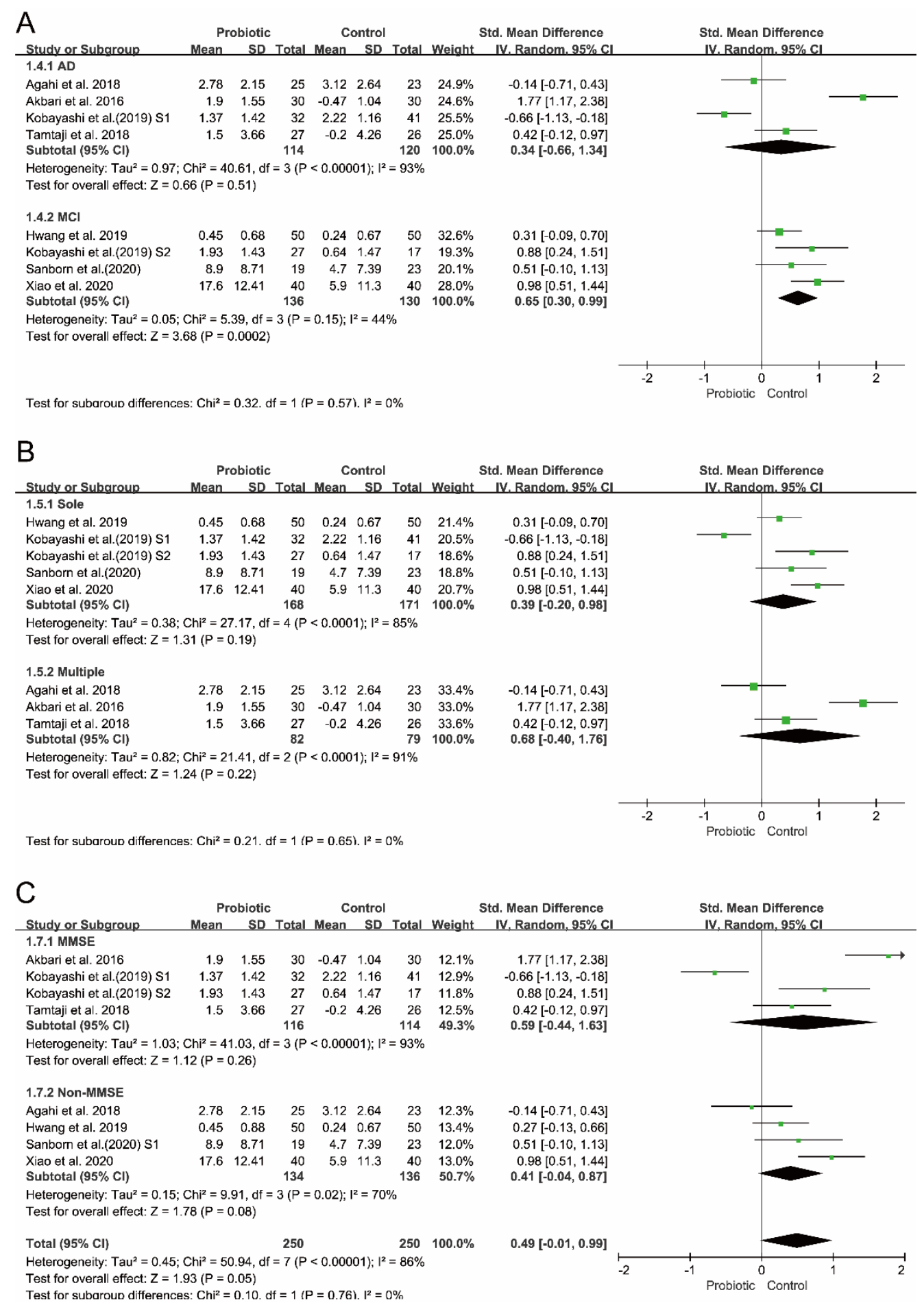

Figure 4. Subgroup analyses of the effect of probiotics on cognition. (A) Subgrouping by type of disease. (B) Subgrouping by strains of probiotics used in RCTs. (C) Subgrouping by cognitive rating scales. 


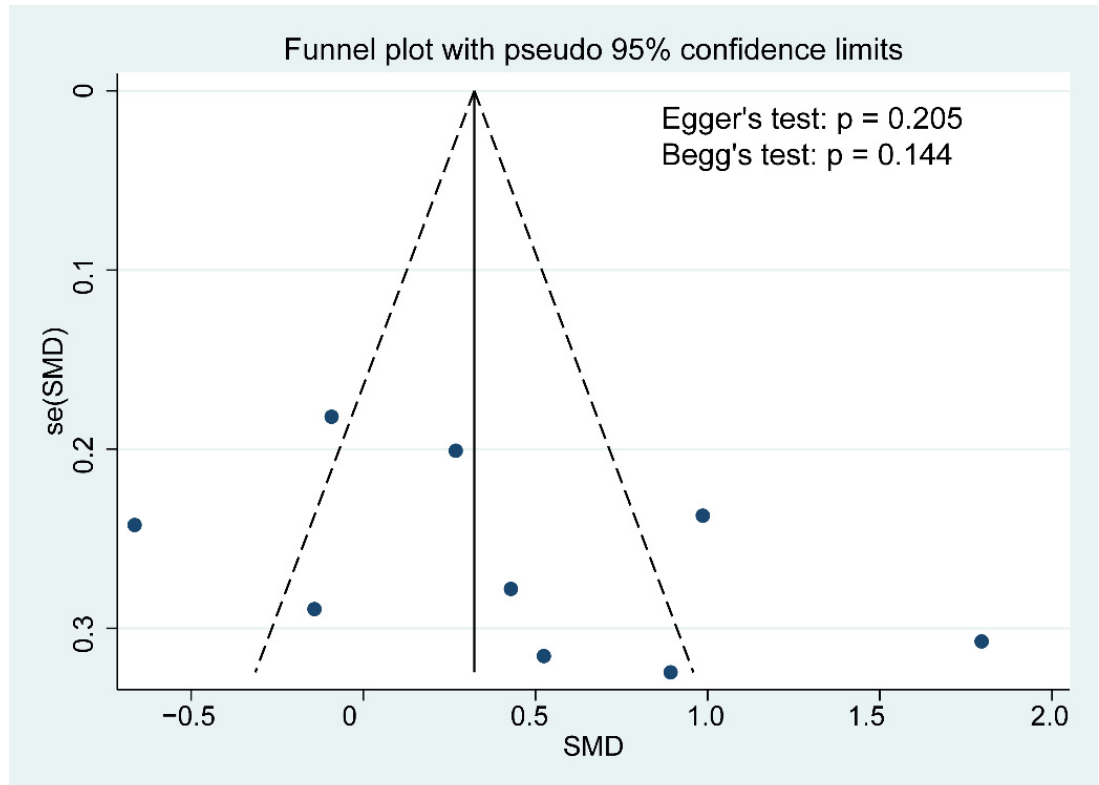

Figure 5. Funnel plot demonstrating publication bias in the meta-analyses. Each circle represents one study; and the vertical line indicates the weighted mean effect. The funnel plot asymmetry was assessed with Begg and Egger tests. A $p$ value $<0.1$ was defined as significant publication bias.

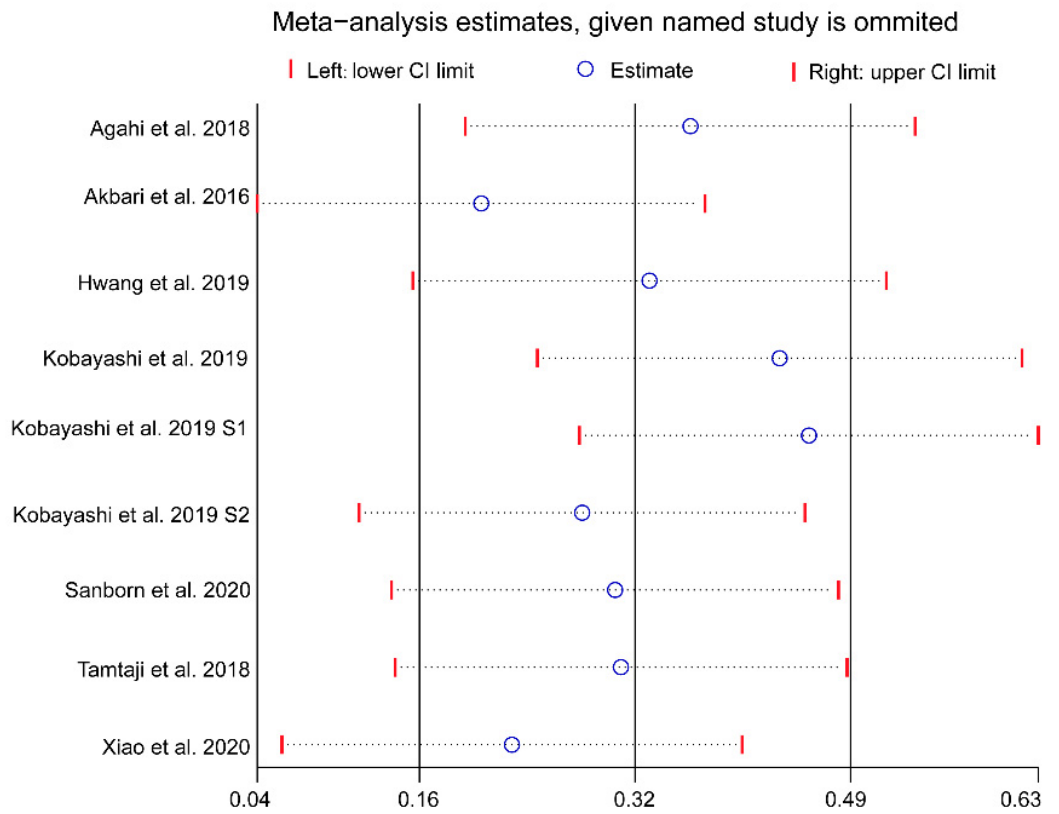

Figure 6. Results of sensitivity analysis using the leave-one-out method. Abbreviations: CI, confidence interval.

\section{Discussion}

In this meta-analysis, we include the most recent RCTs of probiotic and prebiotic supplementation for $\mathrm{MCI}$ and $\mathrm{AD}$. Compared with placebo or control interventions, probiotic supplementation considerably improved cognitive function in the participants with $\mathrm{MCI}$, but it only caused a modest cognitive improvement in those with AD. Furthermore, subgroup analyses conducted to explain the high heterogeneity across the included studies revealed that the extent of cognitive improvement is associated with the number of probiotic strains used (single or multiple), the dosage and duration of the intervention and the severity of the disease ( $\mathrm{AD}$ or $\mathrm{MCI}$ ). Collectively, these findings align with the 
previously reported neuroprotective effects of probiotics and prebiotics in neurological disorders [9-11].

In addition to cognitive improvement, probiotic supplementation altered the fecal microbiota structure and composition in $\mathrm{AD}$ patients. A recent study in a Chinese cohort found the diversity of fecal microbiota was significantly declined in AD patients; it also found reductions in the abundances of specific microbial communities to be associated with the disease severity of AD and MCI [28]. Similarly, a US study reported decreased fecal microbial diversity in patients with AD [29]. However, only one study [26] included in our review reported the changes of gut microbiome composition after probiotic administration. Given that microbiota-targeted interventions using probiotics/prebiotics can improve cognition through the microbiota-gut-brain axis, more attention should be paid to fecal microbiota analyses in future studies.

In the past decade, emerging studies have suggested that dietary probiotic intervention also play a beneficial effect in emotion, cognition, systemic and neural indices in disease states [30]. In addition to the clinical trials for $\mathrm{AD}$ and $\mathrm{MCI}$ reviewed in this study, several recent studies have evaluated the effects of specific probiotics on depression, anxiety and Parkinson's disease. For example, in a randomized, double-blind, placebo-controlled clinical trial [25], daily probiotic administration for 12 weeks considerably improved the MDS-UPDRS scores in patients with Parkinson's disease. Another recent study [10] reported that daily administration of probiotics led to a slight but significant change in symptoms of depression and anxiety, whereas prebiotic administration showed no effect.

Evidence from other investigations also support similar beneficial effects of probiotic administration on disorders of the gut-brain axis. For example, in one RCT [31], healthy volunteers randomly received a mixture of multiple probiotics or placebo for 4 weeks. Compared with the placebo, probiotic consumption significantly reduced reactivity to sad mood in the volunteers. Another study in physically healthy subjects also found that the consumption of a probiotic-containing yogurt for 3 weeks substantially improved mood [32]. An early study of irritable bowel syndrome also provided evidence of the beneficial systemic and immunological effects of probiotics [33]. Interestingly, only individuals with irritable bowel syndrome who received Bifidobacterium infantis 35,624 exhibited a normalization of the interleukin-10 to interleukin-12 ratio. These findings suggest that the widely acknowledged immunological benefits of probiotics are more strain-specific than previously thought [34].

Notably, the well-studied Bifidobacterium and Lactobacillus spp. are most frequently used as potential psychobiotics $[35,36]$. However, not all probiotics have psychobiotic potential. Thus, given the fact that the salutary effects of probiotics on AD are strainspecific, a more efficient probiotic screening method is warranted to develop effective probiotic strategies for AD.

According to the ISAPP definition of probiotics, consuming adequate amounts of probiotics can confer certain health benefits. However, the ISAPP does not specify the functional dose and frequency of probiotic supplementation. Over the past decade, organizations and agencies, such as the ISAPP [6], Health Canada [37], the World Gastroenterology Organization [38] and the Italian Ministry of Health (IMH) [39], have attempted to establish a recommended dosage of probiotics. To ensure safe and effective use of probiotics, the IMH has claimed that the minimum number of viable probiotic cells in food-based probiotics and dietary supplements should be $1 \times 10^{9} \mathrm{CFU}$ per day. Consistently, in our study, all of the included probiotic-treated studies consumed a daily probiotic dose of $1 \times 10^{9} \mathrm{CFU}$ or more. Despite the considerable research progress in the field of probiotic, determining the most effective dose of specific probiotic strains for different disease conditions remains a challenge. Given that certain probiotic strains have synergistic effects on the gut microbiota, multistrain probiotics that promise high efficacy should receive more attention in future studies.

Some limitations in the experimental design of the studies included in this systematic review must be acknowledged. First, some of the trials $[16,23]$ had a small sample size, 
which might restrict the accuracy of the findings. Second, none of the included studies ruled out the interference of other dietary supplements, such as antibiotics, Mediterranean-style diets, other probiotics or fermented foods. Such dietary supplements may have a direct effect on the gut microbiota and metabolic profiles, which can in turn influence the gutbrain axis and related disorders. For instance, the results of a high-quality meta-analysis suggested that Mediterranean diets are negatively correlated with the risk of developing $\mathrm{MCI}$ and $\mathrm{AD}$ [40]. Therefore, such factors should be taken into consideration in future studies. Third, the included studies assessed cognitive function using a variety of rating scales. As the rating scales have different sensitivities and specificities for cognitive impairment, one or more gold-standard rating tools should be established to ensure the stability and reliability of results across studies. Fourth, to better distinguish patients with AD and without dementia, a commonly used clinical diagnosis criteria such as the NINCDSADRDA should be used. However, only four of our included studies [16,23-25] applied the NINCDS-ADRDA criteria. Fifth, none of the included studies ruled out the interference of other lifestyle interventions that can improve cognitive status and possibly even prevent cognitive impairment, dementia and $\mathrm{AD}$ [41], such as mental activities and exercise and specific multinutrient interventions [4]. Sixth, only two of the included studies [17,27] grouped the patients according to disease severity and evaluated the effects of probiotics on them separately. Evidence from previous researches have shown that the health effect of probiotics may differ among different diseases stages [26,27]. Consistently, our findings suggest that probiotic intervention at early stages of $\mathrm{AD}$, such as $\mathrm{MCI}$, could improve cognitive function and delay disease progression. Lastly, four of the included studies $[17,23-25]$ did not report the adverse effects of probiotic administration. Although probiotics have a demonstrable history of safe use as dietary supplements, elderly people have decreased immunity and a high risk of serious adverse effects, such as gastrointestinal side effects, systemic infections and skin complications. Therefore, future studies are encouraged to report the adverse effects of probiotic supplementation [42]. By addressing all of these limitations in the design of future probiotic intervention-based studies, the beneficial effects of probiotics on $\mathrm{AD}$ could be more comprehensively and systematically clarified.

This systematic review has some noteworthy strengths. First, the systematic review and meta-analysis strictly followed the recommendations of the Cochrane handbook and the results were rigorously reported in accordance with the PRISMA statement. Second, we applied a random-effects model and performed sensitivity and subgroup analyses to adequately capture the heterogeneity among the study results. Third, we fully discussed the limitations of the experimental design of the included studies, addressing these methodological limitations may guide future researches.

Despite these strengths, our systematic review has some limitations. First, despite exhaustive literature searches, we might have missed some eligible studies. Second, the features of some included studies may have potential risk of bias due to commercial funding and defects in the experimental design. Third, the format of the data reported by some studies was not suitable for our analyses. Lastly, in terms of the high heterogeneity indicated, our findings should be interpreted with caution.

\section{Conclusions}

Collectively, the results of this meta-analysis indicate that probiotics, when supplemented at adequate amounts for 12 weeks or longer, may improve cognitive function in MCI or AD individuals. However, given the insufficient evidence from current RCTs, further work concerning long-period, large-scale RCTs are warranted to investigate the neuroprotective effects of probiotics in different stages of AD.

Supplementary Materials: The following are available online at https:/ /www.mdpi.com/article/ 10.3390/foods10071672/s1, Supplementary S1: Details of searching strategy and screening process, Table S1: PRISMA checklist. 


\begin{abstract}
Author Contributions: Conceptualization, H.Z. and G.W.; methodology, G.Z.; software, G.Z.; validation, J.Z. and G.W.; data curation, G.Z.; writing—original draft preparation, G.Z.; writing-review and editing, G.W.; visualization, G.Z.; supervision, J.Z.; project administration, G.W.; funding acquisition, G.W. and W.C. All authors have read and agreed to the published version of the manuscript.

Funding: This work was supported by the National Natural Science Foundation of China (No. 31972052, 32021005, 31820103010), the Fundamental Research Funds for the Central Universities (JUSRP22006, JUSRP51501), the National First-class Discipline Program of Food Science and Technology (JUFSTR20180102), the Program of Collaborative Innovation Centre of Food Safety and Quality Control in Jiangsu Province.
\end{abstract}

Conflicts of Interest: The authors declare no conflict of interest.

\title{
References
}

1. Scheltens, P.; Blennow, K.; Breteler, M.M.B.; de Strooper, B.; Frisoni, G.B.; Salloway, S.; Van der Flier, W.M. Alzheimer's Disease. Lancet 2016, 388, 505-517. [CrossRef]

2. Ballard, C.; Gauthier, S.; Corbett, A.; Brayne, C.; Aarsland, D.; Jones, E. Alzheimer's Disease. Lancet 2011, 377, $1019-1031$. [CrossRef] [PubMed]

3. Ngandu, T.; Lehtisalo, J.; Solomon, A.; Levälahti, E.; Ahtiluoto, S.; Antikainen, R.; Bäckman, L.; Hänninen, T.; Jula, A.; Laatikainen, T. A 2 Year Multidomain Intervention of Diet, Exercise, Cognitive Training, and Vascular Risk Monitoring Versus Control to Prevent Cognitive Decline in At-Risk Elderly People (FINGER): A randomised controlled trial. Lancet 2015, 385, 2255-2263. [CrossRef]

4. Soininen, H.; Solomon, A.; Visser, P.J.; Hendrix, S.B.; Blennow, K.; Kivipelto, M.; Hartmann, T.; Hallikainen, I.; Hallikainen, M.; Helisalmi, S.; et al. 24-month intervention with a specific multinutrient in people with prodromal Alzheimer's disease (LipiDiDiet): A randomised, double-blind, controlled trial. Lancet Neurol. 2017, 16, 965-975. [CrossRef]

5. Collins, S.M.; Bercik, P. Intestinal bacteria influence brain activity in healthy humans. Nat. Rev. Gastroenterol. Hepatol. 2013, 10, 326-327. [CrossRef] [PubMed]

6. Hill, C.; Guarner, F.; Reid, G.; Gibson, G.R.; Merenstein, D.J.; Pot, B.; Morelli, L.; Canani, R.B.; Flint, H.J.; Salminen, S.; et al. The International Scientific Association for Probiotics and Prebiotics consensus statement on the scope and appropriate use of the term probiotic. Nat. Rev. Gastroenterol. Hepatol. 2014, 11, 506-514. [CrossRef] [PubMed]

7. Gibson, G.R.; Hutkins, R.W.; Sanders, M.E.; Prescottet, S.L.; Reimer al., R.A.; Salminen, S.J.; Scott, K.; Stanton, C.; Swanson, K.S.; Cani, P.D.; et al. The International Scientific Association for Probiotics and Prebiotics (ISAPP) consensus statement on the definition and scope of prebiotics. Nat. Rev. Gastroenterol. Hepatol. 2017, 14, 491-502. [CrossRef]

8. Swanson, K.S.; Gibson, G.R.; Hutkins, R.; Reimer, R.A.; Sanders, M.E. The International Scientific Association for Probiotics and Prebiotics (ISAPP) consensus statement on the definition and scope of synbiotics. Nat. Rev. Gastroenterol. Hepatol. 2020, 17, 1-15. [CrossRef] [PubMed]

9. Barichella, M.; Pacchetti, C.; Bolliri, C.; Cassani, E.; Iorio, L.; Pusani, C.; Pinelli, G.; Privitera, G.; Cesari, I.; Faierman, S.A. Probiotics and prebiotic fiber for constipation associated with Parkinson disease. Neurology 2016. [CrossRef] [PubMed]

10. Liu, R.T.; Walsh, R.F.L.; Sheehan, A.E. Prebiotics and probiotics for depression and anxiety: A systematic review and meta-analysis of controlled clinical trials. Neurosci. Biobehav. Rev. 2019, 102, 13-23. [CrossRef] [PubMed]

11. Sanders, M.E.; Lenoir-Wijnkoop, I.; Salminen, S.; Merenstein, D.J.; Gibson, G.R.; Petschow, B.W.; Nieuwdorp, M.; Tancredi, D.J.; Cifelli, C.J.; Jacques, P. Probiotics and prebiotics: Prospects for public health and nutritional recommendations. Ann. N. Y. Acad. 2014, 1309, 19-29. [CrossRef]

12. Barbosa, R.S.D.; Vieira-Coelho, M.A. Probiotics and prebiotics: Focus on psychiatric disorders- A systematic review. Nutr. Rev. 2019, 78, 437-450. [CrossRef]

13. Krüger, J.; Hillesheim, E.; Pereira, A.; Camargo, C.Q.; Rabito, E.I. Probiotics for dementia: A systematic review and meta-analysis of randomized controlled trials. Nutr. Rev. 2020, 79, 160-170. [CrossRef] [PubMed]

14. Den, H.; Dong, X.; Chen, M.; Zou, Z. Efficacy of probiotics on cognition, and biomarkers of inflammation and oxidative stress in adults with Alzheimer's disease or mild cognitive impairment-a meta-analysis of randomized controlled trials. Aging 2020, 12, 4010-4039. [CrossRef] [PubMed]

15. González, C.; Roman, P.; Rueda-Ruzafa, L.; Rodriguez-Arrastia, M.; Cardona, D. Effects of probiotics supplementation on dementia and cognitive impairment: A systematic review and meta-analysis of preclinical and clinical studies. Prog. Neuro Psychopharmacol. Biol. Psychiatry 2021, 108, 110189. [CrossRef]

16. Ton, A.; Campagnaro, B.P.; Alves, G.A.; Aires, R.; Vasquez, E.C. Oxidative Stress and Dementia in Alzheimer's Patients: Effects of Synbiotic Supplementation. Oxidative Med. Cell. Longev. 2020, 2020, 1-14. [CrossRef] [PubMed]

17. Sanborn, V.; Azcarate-Peril, M.A.; Updegraff, J.; Manderino, L.; Gunstad, J. Randomized Clinical Trial Examining the Impact of Lactobacillus rhamnosus GG Probiotic Supplementation on Cognitive Functioning in Middle-aged and Older Adults. Neuropsychiatr. Dis. Treat. 2020, 16, 2765-2777. [CrossRef] [PubMed] 
18. Xiao, J.; Katsumata, N.; Bernier, F.; Ohno, K.; Yamauchi, Y.; Odamaki, T.; Yoshikawa, K.; Ito, K.; Kaneko, T. Probiotic Bifidobacterium breve in Improving Cognitive Functions of Older Adults with Suspected Mild Cognitive Impairment: A Randomized, Double-Blind, Placebo-Controlled Trial. J. Alzheimers Dis. 2020, 77, 139-147. [CrossRef] [PubMed]

19. Vrabel, M. Preferred Reporting Items for Systematic Reviews and Meta-Analyses: The PRISMA Statement. Revista Española de Nutrición Humana y Dietética 2009, 18, e123.

20. Higgins, J.; Green, S. Cochrane Handbook for Systematic Reviews of Interventions; Version 5.1.0; The Cochrane Collaboration: London, UK, 2013.

21. Higgins, J.; Thompson, S.G. Quantifying heterogeneity in a meta-analysis. Stat. Med. 2002, 21, 1539-1558. [CrossRef] [PubMed]

22. Bradburn, S.; Murgatroyd, C.; Ray, N. Neuroinflammation in mild cognitive impairment and Alzheimer's disease: A meta-analysis. Ageing Res. Rev. 2019, 50, 1-8. [CrossRef] [PubMed]

23. Agahi, A.; Hamidi, G.A.; Daneshvar, R.; Hamdieh, M.; Soheili, M.; Alinaghipour, A.; Esmaeili Taba, S.M.; Salami, M. Does Severity of Alzheimer's Disease Contribute to Its Responsiveness to Modifying Gut Microbiota? A Double Blind Clinical Trial. Front. Neurol. 2018, 9, 662. [CrossRef] [PubMed]

24. Akbari, E.; Asemi, Z.; Daneshvar Kakhaki, R.; Bahmani, F.; Kouchaki, E.; Tamtaji, O.R.; Hamidi, G.A.; Salami, M. Effect of Probiotic Supplementation on Cognitive Function and Metabolic Status in Alzheimer's Disease: A Randomized, Double-Blind and Controlled Trial. Front. Aging Neurosci. 2016, 8, 256. [CrossRef] [PubMed]

25. Reza Tamtaji, O.; Reza, H.-s.; Naghmeh, M.; Ebrahim, K.; Fereshteh, B.; Esmat, A.; Maryam, T.-E.; Zatollah, A. Probiotic and selenium co-supplementation, and the effects on clinical, metabolic and genetic status in Alzheimer's disease: A randomized, double-blind, controlled trial. Clin. Nutr. 2019, 38, 2569-2575. [CrossRef] [PubMed]

26. Hwang, Y.H.; Park, S.; Paik, J.W.; Chae, S.W.; Kim, D.H.; Jeong, D.G.; Ha, E.; Kim, M.; Hong, G.; Park, S.H.; et al. Efficacy and Safety of Lactobacillus Plantarum C29-Fermented Soybean (DW2009) in Individuals with Mild Cognitive Impairment: A 12-Week, Multi-Center, Randomized, Double-Blind, Placebo-Controlled Clinical Trial. Nutrients 2019, 11, 305. [CrossRef]

27. Kobayashi, Y.; Kuhara, T.; Oki, M.; Xiao, J.Z. Effects of bifidobacterium breve a1 on the cognitive function of older adults with memory complaints: A randomised, double-blind, placebo-controlled trial. Benef. Microbes 2019, 10, 511-520. [CrossRef]

28. Liu, P.; Wu, L.; Peng, G.; Han, Y.; Wang, B. Altered microbiomes distinguish Alzheimer's disease from amnestic mild cognitive impairment and health in a Chinese cohort. Brain Behav. Immun. 2019, 80, 633-643. [CrossRef]

29. Vogt, N.M.; Kerby, R.L.; Dill-McFarland, K.A.; Harding, S.J.; Merluzzi, A.P.; Johnson, S.C.; Carlsson, C.M.; Asthana, S.; Zetterberg, H.; Blennow, K.; et al. Gut microbiome alterations in Alzheimer's disease. Sci. Rep. 2017, 7, 13537. [CrossRef] [PubMed]

30. Sarkar, A.; Lehto, S.M.; Harty, S.; Dinan, T.G.; Cryan, J.F.; Burnet, P.W.J. Psychobiotics and the Manipulation of Bacteria-Gut-Brain Signals. Trends Neurosci. 2016, 39, 763-781. [CrossRef] [PubMed]

31. Lsa, B.; Rsa, B.; Svh, C.; Jab, D.; Lsca, B. A randomized controlled trial to test the effect of multispecies probiotics on cognitive reactivity to sad mood. Brain Behav. Immun. 2015, 48, 258-264.

32. Benton, D.; Williams, C.; Brown, A. Impact of consuming a milk drink containing a probiotic on mood and cognition. Eur. J. Clin. Nutr. 2007, 61, 355-361. [CrossRef]

33. O'Mahony, L.; Mccarthy, J.; Kelly, P.; Hurley, G.; Luo, F.; Chen, K.; O’Sullivan, G.; Kiely, B.; Collins, J.K.; Shanahan, F. Lactobacillus and bifidobacterium in irritable bowel syndrome: Symptom responses and relationship to cytokine profiles. Gastroenterology 2005, 128, 541-551. [CrossRef]

34. Maidens, C.; Childs, C.; Przemska, A.; Dayel, I.B.; Yaqoob, P. Modulation of vaccine response by concomitant probiotic administration. Br. J. Clin. Pharmacol. 2013, 75, 663-670. [CrossRef]

35. Dinan, T.G.; Stanton, C.; Cryan, J.F. Psychobiotics: A Novel Class of Psychotropic. Biol. Psychiatry 2013, 74, 720-726. [CrossRef]

36. Burnet, P.; Cowen, P.J. Psychobiotics highlight the pathways to happiness. Biol. Psychiatry 2013, 74, 708-709. [CrossRef]

37. Canada, H. Accepted Claims about the Nature of Probiotic Microorganisms in Food. Available online: http://www.hc-sc.gc.ca/ (accessed on 20 May 2021).

38. Labrecque, D.R.; Abbas, Z.; Anania, F.; Ferenci, P.; Khan, A.G.; Goh, K.L.; Hamid, S.S.; Isakov, V.; Lizarzabal, M.; PenAranda, M.M. World Gastroenterology Organisation Global Guidelines. J. Clin. Gastroenterol. 2014, 48, 204-217. [CrossRef]

39. Ohr, L.M. Health Benefits of Probiotics and Prebiotics. Food Technol. 2010, 64, 59-64.

40. Singh, B.; Parsaik, A.K.; Mielke, M.M.; Erwin, P.J.; Roberts, R.O. Association of Mediterranean Diet with Mild Cognitive Impairment and Alzheimer's Disease: A Systematic Review and Meta-Analysis. J. Alzheimers Dis. 2014, 39, 271-282. [CrossRef] [PubMed]

41. Kivipelto, M.; Mangialasche, F.; Ngandu, T. Lifestyle interventions to prevent cognitive impairment, dementia and Alzheimer disease. Nat. Rev. Neurol. 2018, 14, 653-666. [CrossRef] [PubMed]

42. Yusufov, M.; Weyandt, L.L.; Piryatinsky, I. Alzheimer's Disease and Diet: A Systematic Review. Int. J. Neurosci. 2016, 127, 161-175. [CrossRef] 